\title{
Effect of Nano-silicate on the Mechanical, Electrical and Thermal Properties of Epoxy/Micro-silica Composite
}

\author{
Jae-Jun Park ${ }^{+}$ \\ Department of Electrical and Electronic Engineering, Joongbu University, Geumsan 312-702, Korea
}

Received April 17, 2012; Accepted May 7, 2012

\begin{abstract}
In order to develop electrical insulation materials, epoxy/micro-silica composite (EMC) and epoxy/micro-silica/nanosilicate composite (EMNC) were prepared, and their tensile and flexural strength, AC insulation breakdown strength and thermal conductivity and thermal expansion coefficient were compared. Nano-silicate was prepared in an epoxy matrix by our AC electric field process. All properties of the neat epoxy were improved by the addition of micro-silica, which was improved much further by the addition of nano-silicate to the EMC system.
\end{abstract}

Keywords: High voltage insulation material, Epoxy composite, Micro-silica, Nano-silicate, Thermal expansion coefficient

\section{INTRODUCTION}

Various kinds of inorganic fillers such as silica $\left(\mathrm{SiO}_{2}\right)$ [1], alumina $\left(\mathrm{Al}_{2} \mathrm{O}_{3}\right)$ [2], mica [3], aluminum nitride (AlN) [4], titanium dioxide $\left(\mathrm{TiO}_{2}\right)$ [5], etc. have been widely used for conventional polymer composites in order to apply them to insulation materials. In particular, epoxy composite systems with micro-sized silica particles are the most well-known for high voltage (HV) applications such as mold-type transformers, current transformers (CT), potential transformers (PT), metering out-fit (MOF) and gas switching gears [6,7], as well as low and medium voltage (LV and MV) applications such as pin and post type insulators, bushings, instrument transformers for current and voltage measurement, bus support assemblies,and switching and protection equipments $[8,9]$. Usually, the composites are used by loading micro-silica with ordinary particle size above $1 \mu \mathrm{m}$ and up to 100 $\mu \mathrm{m}$., $65 \sim 80 \mathrm{wt} \%$ of micro-silica can be loaded in an epoxy matrix to achieve the same low level thermal expansion as copper or aluminum parts, which prevents exfoliating between the epoxy casting part and the metallic parts. Many electric apparatus

${ }^{\dagger}$ Author to whom all correspondence should be addressed: E-mail: jjpark@joongbu.ac.kr

Copyright @2012 KIEEME. All rights reserved. This is an open-access article distributed under the terms of the Creative Commons Attribution Non-Commercial
License (http://creativecommons.org/licenses/by-nc/3.0) which permits unrestricted noncommercial use, distribution, and reproduction in any medium, provided the original work is properly cited are generally operated at $40 \sim 60^{\circ} \mathrm{C}$ and are exposed to various heat-cycles from outside environmental temperatures [10]. In addition, the micro-silica can also enhance the electrical and thermal properties, hydrothermal aging and UV resistance of an epoxy matrix during the manufacturing process or their service lives.

recently, many researchers have been interested in the application of nano-sized fillers in an epoxy matrix [11-13]. Our previous work [11] showed that epoxy nanocomposites were remarkably improved by the addition of intercalated silicates. T. Tanaka and co-workers [12] showed that epoxy/layered silicate nanocomposite had much better insulation breakdown time than epoxy resin without fillers in needle-plate electrode geometry. Zou et al [13] reported the influence of humidity on the dielectric properties of epoxy nanocomposites filled with silica. Furthermore, a new concept involving the mixture of micro- and nano-fillers for epoxy-based composites has been considered by many researchers $[14,15]$. They reported that nano-silica or multilayered silicate improved the electrical and mechanical properties of epoxy resin/ silica microcomposites.

In this study, we prepared an epoxy/micro-silica composite (EMC), into which nano-silicate was mixed to prepare epoxy/ micro-silica/nano-silicate composites (EMNC) for use as insulation materials of heavy electric equipments. The mechanical, electrical and thermal properties of these composites were compared. 


\section{EXPERIMENTS}

\subsection{Materials}

A commercial DGEBA (diglycidyl ether of bisphenol A) type epoxy resin, YD 128 (Kukdo Chem. Co.) was used. The equivalent weight was 184 190 eew and the viscosity was $11,500 \sim 13,500 \mathrm{cps}$ at $25^{\circ} \mathrm{C}$. The curing agent was Me-THPA (3- or 4-methyl-1,2,3,6tetrahydrophthalic anhydride) whose grade name was $\mathrm{HN}$ 2200 (Hitachi Chem. Co.). It is widely used in the field of electric insulation. The accelerator was BDMA (benzyl-dimethyl amine, Kukdo Chem. Co.). CA0020 grade micro-silica with an average particle size of $3 \mu \mathrm{m}$ was purchased from Sibelco Asia and was dried at $110^{\circ} \mathrm{C}$ for $24 \mathrm{~h}$ in a vacuum oven and stored in desiccator before use. Cloisite ${ }^{\circledR} 10 A$ (Southern Clay Products, Inc., USA) was used as a multilayered silicate, which was a natural montmorillonite modified with 2MBHT (dimethyl-benzyl-hydrogenated tallow quaternary ammonium) as a sort of quaternary ammonium salt. It was also dried at $110^{\circ} \mathrm{C}$ for $24 \mathrm{~h}$ in a vacuum oven and stored in a desiccator before use.

\subsection{Preparation of EMC and EMNC}

Figure 1 shows the preparation process for EMC and EMNC. To prepare EMC, DGEBA (100 g) and micro-silica (65 g) were well-mixed with a high-speed agitator at 5,000 rpm for $30 \mathrm{~min}$, and then THPA ( $80 \mathrm{~g})$ and BDMA $(0.9 \mathrm{~g})$ were added and mixed for $5 \mathrm{~min}$. The matrix micro-silica weight ratio of the epoxy was 1.0:0.36. The mixture was poured into a mold and degassed in a vacuum oven and cured at $120^{\circ} \mathrm{C}$ for $2 \mathrm{~h}$,followed by continual postcuring at $150^{\circ} \mathrm{C}$ for $2 \mathrm{~h}$.

In order to prepare EMNC, epoxy base resin (DGEBA, $50 \mathrm{~g}$ ) and Cloisite $10 \mathrm{~A}(1.0 \mathrm{~g})$ were well-mixed in a bottle with a mechanical agitator for $30 \mathrm{~min}$ and then treated by an AC electric field process, which was developed by us [16]. The AC electric field was generated by a high voltage (HV) generator with the following conditions; (1) inter-electrode distance: $50 \mathrm{~mm}$, (2) application voltage: $11 \mathrm{kV}$, (3) frequency: $1 \mathrm{kHz}$, and (4) application time: $60 \mathrm{~min}$. Then the mixture was degassed in a vacuum oven for $30 \mathrm{~min}$. DGEBA (50 g) and micro-silica ( $65 \mathrm{~g}$ ) were well-mixed in another bottle with a high-speed agitator at 5,000 rpm for 30 min, and the mixture in the first bottle was added to the bottle and mixed at 5,000 rpm for $30 \mathrm{~min}$. Then, THPA (80 g) and BDMA $(0.9 \mathrm{~g})$ were mixed for $5 \mathrm{~min}$ and cured in the same conditions as the EMNC preparation. The matrix: micro-silica nano-silicate weight ratio of the epoxy was 1.0:0.36:0.0053.

\subsection{Instrumental analysis}

Dynamic mechanical analysis (DMA2980, TA Instrument Ltd.) was carried out in shear mode at the frequency of $1.0 \mathrm{~Hz}$ and heating rate of $10{ }^{\circ} \mathrm{C} / \mathrm{min}$. The sample dimension was $12.5 \times 7.0$ $\times 3.0 \mathrm{~mm}$ and the air purge rate was $110 \mathrm{ml} / \mathrm{min}$.

Tensile and flexural tests were carried out by a universal testing machine (SHM-C-500, Shamhan Tech, Korea). Specimens for tensile tests were prepared under the recommendation of JIS B7502 and they were tested at a crosshead speed of $10 \mathrm{~mm} / \mathrm{min}$ at $23^{\circ} \mathrm{C}$ and $50 \%$ relative humidity. Specimens for flexural tests were prepared by three point bending method with the recommendation of JIS B7507 at a size of $70 \times 10 \times 4 \mathrm{~mm}$. The span length was $50 \mathrm{~mm}$ and crosshead speed was $10 \mathrm{~mm} / \mathrm{min}$ at the same temperature and humidity in the tensile test.

An AC insulation breakdown test was carried out in anarrangement of sphere to sphere electrodes [17]. The electrode's diameter was $7.40 \mathrm{~mm}$ and the electrode distance was $0.25 \mathrm{~mm}$. The specimen was dipped into insulating oil and HV was applied

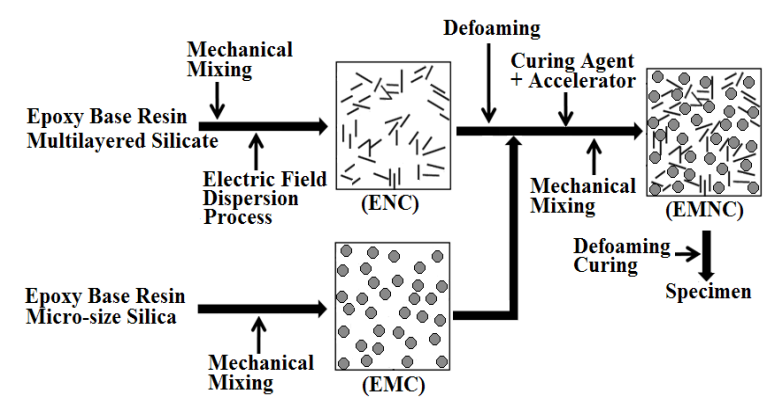

Fig. 1. Preparation process for EMC and EMNC.

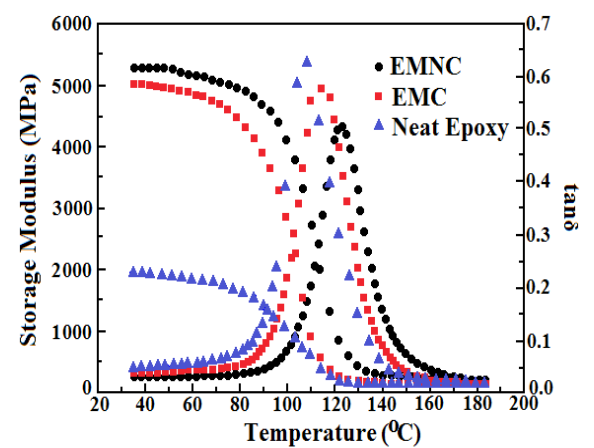

Fig. 2. DMA curves for epoxy composites, which were cured at $120^{\circ} \mathrm{C}$ for $2 \mathrm{~h}$ and postcured at $150{ }^{\circ} \mathrm{C}$ for $2 \mathrm{~h}$.

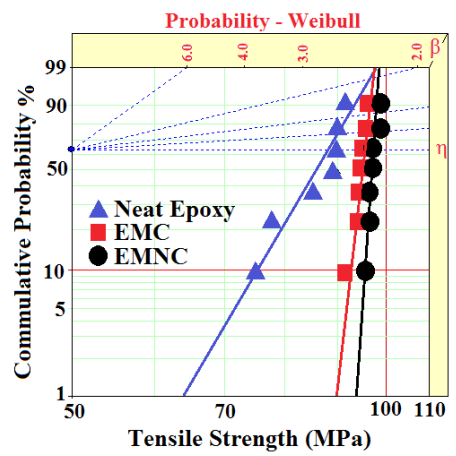

Fig. 3. Tensile strength of epoxy composites, which were cured at $120^{\circ} \mathrm{C}$ for $2 \mathrm{~h}$ and postcured at $150^{\circ} \mathrm{C}$ for $2 \mathrm{~h}$.

by an AC Endurance Voltage Tester (Haefely, Germany) at a rising speed of $1 \mathrm{kV} / \mathrm{s}$ until electrical breakdown took place. Tensile and flexural strength and insulation breakdown data were estimated by Weibull statistical analysis [18].

Thermal conductivity was estimated by a Xenon Flash Instrument (LFA 447 NanoFlash, Netzsch Co., Germany). The specimen thickness was $0.92 \mathrm{~mm}$ and the diameter was $12.7 \mathrm{~mm}$. Thermal expansion coefficient was measured by TA TMA 2940 (USA).

\section{RESULTS AND DISCUSSION}

Figure 2 shows DMA curves for epoxy composites, which were cured at $120^{\circ} \mathrm{C}$ for $2 \mathrm{~h}$ and postcured at $150^{\circ} \mathrm{C}$ for $2 \mathrm{~h}$. The storage modulus of the neat epoxy at $40^{\circ} \mathrm{C}$ (in glass state) was 1,924 MPa, and that of EMC was 5,007 MPa, which was 2.60 times higher. That of EMNC was 5,254 MPa, which was $247 \mathrm{MPa}$ higher than that of EMC. As the atmosphere temperature increased, the stor- 


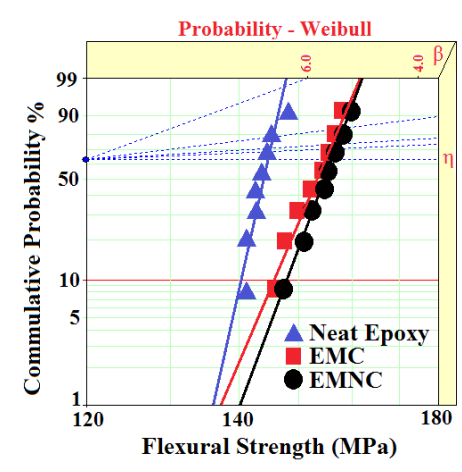

Fig. 4. Flexural strength of epoxy composites, which were cured at $120^{\circ} \mathrm{C}$ for $2 \mathrm{~h}$ and postcured at $150^{\circ} \mathrm{C}$ for $2 \mathrm{~h}$.

Table 1. Weibull parameters obtained from the flexural strength in Fig. 4.

\begin{tabular}{cccc|}
\hline System & $\begin{array}{c}\text { Scale parameter } \\
(\mathrm{kV} / \mathrm{mm})\end{array}$ & Shape parameter & $\begin{array}{c}\text { B10 value } \\
(\mathrm{kV} / \mathrm{mm})\end{array}$ \\
\hline \hline Neat epoxy & 147.9 & 72.6 & 143 \\
EMC & 158.1 & 38.2 & 149 \\
ENMC & 159.2 & 43 & 151 \\
\hline
\end{tabular}

age modulus $\left(G^{\prime}\right)$ decreased and abruptly dropped, and at the same time, the loss modulus $\left(G^{\prime \prime}\right)$ abruptly increased in the glass transition state. The glass

transition temperature (Tg) was estimated from the peak temperature of $\tan \delta$, which was expressed as $\tan \delta=\mathrm{G}^{\prime \prime} / \mathrm{G}^{\prime}$. The Tg value of the neat epoxy resin was $108.5^{\circ} \mathrm{C}$, which was increased by the addition of micro-silica, and increased much more by the addition of nano-silicate. The Tg of the EMC was $112.7^{\circ} \mathrm{C}$ and that of the EMNC was $122.2^{\circ} \mathrm{C}$. When micro-silica was added to the epoxy matrix, the micro-silica could anchor the epoxy chains by the hydrogen bonding between silanol groups on the silica surface and hydroxyl groups in the epoxy matrix so that the mobility of the epoxy chains became disturbed. The anchoring effect increased when the nano-silicate was added, so the Tg value increased.

Figure 3 shows Weibull plots of tensile strength for epoxy composites, from which the parameters such as shape and scale parameters and B10 value were obtained. Here, the shape parameter could be obtained from the slope,which indicated the data distribution, and the scale parameter represented the tensile strength by which there was a $63.2 \%$ cumulative probability of failure. The B10 value referred to the tensile strength at which $10 \%$ would fail ( $90 \%$ would survive) under a given stress. The statistical analysis showed that the scale parameter of the neat epoxy was 88.2 MPa with the shape parameter of 14.4, and that of the EMC was 95.5 MPa with the shape parameter of 72.0. As the nano-silicate was added to the EMC, the scale parameter of the EMNC increased to 97.2 MPa with the shape parameter of 97.2. These meant that the anchoring effect of the micro-silica and nano-silicate took part in the immobility of polymer chains as explained in the DMA results of Fig. 2.

According to the addition of micro-silica and nano-silicate, the same tendency was observed in the flexural strength as shown in Fig. 4, and the Weibull parameters obtained from Figure 4 are listed on Table 1.

The statistical analysis data for the AC insulation breakdown strength tested at $30^{\circ} \mathrm{C}$ are shown in Fig. 5 . The scale parameter of the neat epoxy was $44.5 \mathrm{kV} / 0.25 \mathrm{~mm}$ in the neat epoxy with the shape parameter of 13.6, and that of the EMC was $71.4 \mathrm{kV} / 0.25$

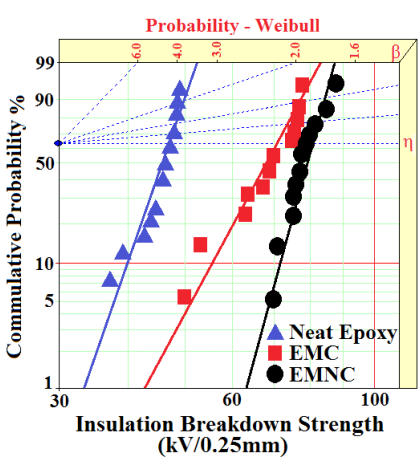

Fig. 5. Weibull statistical analyses of AC insulation breakdown strength for epoxy composites at $30^{\circ} \mathrm{C}$ insulating oil.

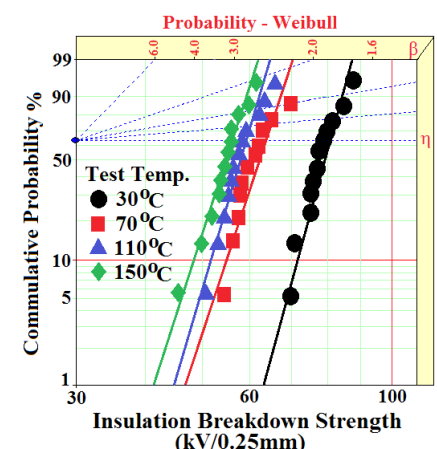

Fig. 6. Weibull statistical analyses of AC insulation breakdown strength for the EMNC at various insulating oil temperature.

$\mathrm{mm}$ with the shape parameter of 8.2. As the nano-silicate was added to the EMC, the scale parameter of the EMNC increased to $80.6 \mathrm{kV} / 0.25 \mathrm{~mm}$ with the shape parameter of 16.7. The improvement of the scale parameter for breakdown strength was due to the electron blocking by the sphere-like silica particles, and there was more improvement by the sheet-like silicates. That is, if an electrical breakdown was initiated, it would be propagated rapidly and until finally breakdown occurred [19]. However, the silica and silicate particles retarded the breakdown rate. Therefore, the EMNC could be used as an excellent insulation material. In addition, the higher the gradient of the shape parameter became, the more homogeneous the breakdown strength data were. These results meant that the nano-sized silicates were evenly dispersed among the micro-silica particles and provided improved electrical breakdown characteristics to the micro-silica system.

The effect of ambient temperature on the AC insulation breakdown strength in the EMNC system was studied at $(\bullet) 30^{\circ} \mathrm{C}$, ( $\bullet$ ) $70^{\circ} \mathrm{C},(\Delta) 110^{\circ} \mathrm{C}$ and $(\star) 150^{\circ} \mathrm{C}$, and the Weibull statistical analyses are shown in Fig. 6. The Weibull parameters are listed in Table 2. As the ambient temperature increased, the scale parameter increased. Compared to the result at $30^{\circ} \mathrm{C}$, the AC breakdown strength at $70^{\circ} \mathrm{C}$ was $20 \%$ lowered, and that at $150{ }^{\circ} \mathrm{C}$ was $28 \%$ lowered. This was because the mobilization of the epoxy chains increased at higher temperature.

In order to apply the epoxy composites to as electrical insulation materials, thermal conductivity of the materials should be considered, because the generated heat during the operation of electrical equipment could cause polymer degradation [20]. Therefore, the generated heat should be removed from the core of the electrical equipment. When micro-silica was added to the epoxy matrix, thermal conductivity was largely increased, and much more increment was achieved by the addition of nano- 
Table 2. Weibull parameters for the AC insulation breakdown strength in EMNC system obtained from Fig. 6.

\begin{tabular}{cccc}
\hline $\begin{array}{c}\text { Temperature } \\
\left({ }^{\circ} \mathrm{C}\right)\end{array}$ & $\begin{array}{c}\text { Scale parameter } \\
(\mathrm{kV} / \mathrm{mm})\end{array}$ & Shape parameter & $\begin{array}{c}\text { B10 value } \\
(\mathrm{kV} / \mathrm{mm})\end{array}$ \\
\hline 30 & 80.6 & 16.7 & 70.5 \\
70 & 63.8 & 14.0 & 54.4 \\
110 & 60.9 & 13.4 & 51.6 \\
150 & 58.1 & 13.4 & 49.2 \\
\hline
\end{tabular}

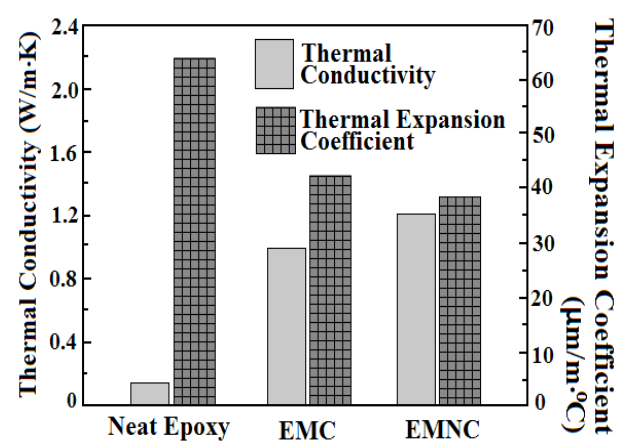

Fig. 7. Thermal conductivity and thermal expansion coefficient for epoxy composites.

silicate as shown in Fig. 7. This meant that the micro-silica and the nano-silicate acted as heat transfer paths.

Furthermore, the thermal expansion coefficient (CTE) of the material should also be considered for insulation materials, because the heat-cycle during the service life could cause exfoliating between the epoxy casting part and the metallic parts [10]. Fig. 7 shows that CTE of the EMC was largely decreased, and much more decrement was achieved by the addition of nanosilicate.

\section{CONCLUSIONS}

Epoxy/micro-silica composite (EMC) and epoxy/micro-silica/ nano-silicate composite (EMNC) were prepared, and their mechanical, electrical and thermal properties were compared. The storage modulus of the neat epoxy at $40{ }^{\circ} \mathrm{C}$ (in glass state) was 1,924 MPa, and that of EMC was 5,007 MPa, which was 2.60 times higher. That of EMNC was 5,254 MPa, which was $247 \mathrm{MPa}$ higher than that of EMC. Weibull statistical analysis showed that the tensile strength of the neat epoxy was $88.2 \mathrm{MPa}$, and those of the EMC and EMNC were 95.5 MPa and 97.2 MPa, respectively. The same tendency was observed in the flexural strength: those for the neat epoxy, EMC and EMNC were 147.9 MPa, 158.1 MPa and 159.2 MPa, respectively. Weibull statistical analysis revealed that the AC insulation breakdown strength of the neat epoxy was 44.5 $\mathrm{kV} / 0.25 \mathrm{~mm}$, and those of the EMC and EMNC were respectively $71.4 \mathrm{kV} / 0.25 \mathrm{~mm}$ and $80.6 \mathrm{kV} / 0.25 \mathrm{~mm}$. The improvements in the thermal conductivity and thermal expansion coefficient were also achieved by addition of micro-silica and nano-silicate.

\section{ACKNOWLEDGMENT}

This work was supported by Joongbu University (2011).

\section{REFERENCES}

[1] P. O. Henk, T. W. Kortsen and T. Kvarts, High Perform. Polym., 11, 281 (1999) [DOI: 10.1088/0954-0083/11/3/304].

[2] M. Ehsani, Z. Farhadinejad, S. Moemen-bellah, S. M. Bagher alavi, M. M. S. Shrazi and H. Borsi, $26^{\text {th }}$ Internal Power System Conference, Tehran, Iran, 11-E-CAM-2359 (2011).

[3] P. Bajaj, N. K. Jha and A. Kumar, J. Appl. Polym. Sci., 56, 1339 (1995) [DOI: 10.1002/app.1995.070561015].

[4] Y. Xu, D. D. L. Chung and C. Mroz, Composites: Part A, 32, 1749 (2001) [DOI: http://dx.doi.org/10.1016/S1359835X(01)00023-9].

[5] A. A. Wazzan, H. A. Al-Turaif and A. F. Abdelkader, PolymerPlastics Technology and Engineering, 45, 1155 (2006) [DOI:10.1 080/03602550600887285].

[6] R. Sarathi, R. K. Sahu and P. Rajeshkumar, Mater. Sci. Eng.: A, 445, 567 (2007) [DOI: 10.1016/j.msea.2006.09.077].

[7] N. Hayakawa, H. Maeda, S. Chigusa and H. Okubo, Cryogenics, 40, 167 (2000) [DOI: 10.1016/s0011-2275(00)00024-2].

[8] G. Iyer, R. S. Gorur, R. Richert, A. Krivda and L. E. Schmidt, IEEE Trans. Dielectr. Electr. Insul., 18, 659 (2011) [DOI: 10.1109/ TDEI.2011.5931050].

[9] D. A. Bolon, , IEEE Trans. Dielectr. Electr. Insul., 11, 10 (1995) [DOI: 10.1109/57.400759].

[10] J. J. Park, K. G. Yoon and J. Y. Lee, Trans. Electr. Electron. Mater. 12, 98 (2011) [DOI: 10.4313/TEEM.2011.12.3.98].

[11] J. J. Park, S. S. Kwon and J. Y. Lee, Trans. Electr. Electron. Mater. 12, 135 (2011) [DOI: http://dx.doi.org/10.4313/TEEM.2011.12.4. 135].

[12] T. Imai, F.Sawa, T.Ozaki, T.Shimizu, R. Kido, M. Kozako, and T. Tanaka, IEEE Trans. Dielectr. Electr. Insul., 13, 445 (2006) [DOI:10.1109/TDEI.2006.1624291].

[13] C. Zou, J.C. Fothergill and S. W. Rowe, IEEE Trans. Dielectr. Electr. Insul., 15, 106 (2008) [DOI: 10.1109/T-DEI.2008.4446741].

[14] J. Castellon, H. N. Nguyen, S. Agnel, A. Toureille, M. Fr?chette, S. Savoie, A. Krivda and L. E. Schmidt, , IEEE Trans. Dielectr. Electr. Insul., 18, 651 (2011) [DOI: 10.1109/TDEI.2011.5931049].

[15] T. Imai, F. Sawa, T. Ozaki, T. Shimizu, S. Kuge, M. Kozako, and Tanaka, IEEJ Trans. Fund. Mater., 126, 1136 (2006) [DOI: 10.1541/ieejfms.126.1136].

[16] J. J. Park and J. Y. Lee, IEEE Trans. Dielectr. Electr. Insul. 17, 1516 (2010) [DOI: 10.1109/TDEI.2010.5595553].

[17] J. J. Park, C. H. Lee, J. Y. Lee and H. D. Kim, IEEE Trans. Dielectr. Electr. Insul. 18, 667 (2011) [DOI: 10.1109/TDEI.2011.5931051].

[18] T. Imai, F. Sawa, T. Ozaki, T. Shimizu, R. Kido, M. Kozako and Tanaka, Proceedings of 2005 International Symposium on Electrical Insulating Materials, p.1136 (2006) [DOI: 10.1109/ ISEIM.2005. 193387].

[19] Y. Chen, T. Imai, Y. Ohki, and T. Tanaka, IEEE Trans. Dielectr. Electric. Insul., 17, 1509 (2010) [DOI: 10.1109/TDEI.2010. 5595552]

[20] C. Y. Hsieh and S. L. Chung, J. Appl. Polym. Sci., 102, 4734 (2006) [DOI: 10.1002/app.25000]. 